Supporting Information

\title{
A Focused Ion Beam-Scanning Transmission Electron Microscopy with Energy-Dispersive X-ray Spectroscopy Study on Technetium Incorporation within Iron Oxides through $\mathrm{Fe}(\mathrm{OH}) 2(\mathrm{~s})$ Mineral Transformation
}

Guohui Wang $^{1 *}$, Matthew J. Olszta ${ }^{1}$, Sarah A. Saslow ${ }^{1}$, Dong-Sang Kim ${ }^{1}$, Mark E. Bowden ${ }^{1}$, Wooyong $\mathrm{Um}^{2}$, Jing Wang ${ }^{1}$, and Albert A. Kruger ${ }^{3}$

${ }^{1}$ Pacific Northwest National Laboratory, Richland, WA, 99352, United States

${ }^{2}$ Division of Advanced Nuclear Engineering (DANE), Pohang University of Science and Technology (POSTECH), Pohang, South Korea

${ }^{3}$ United States Department of Energy, Office of River Protection, Richland, WA 99352, United States

*Corresponding author: Guohui Wang

Address: Pacific Northwest National Laboratory, P.O. Box 999, P7-54, 902 Battelle Boulevard, Richland, WA 99352

E-mail: guohui.wang@pnnl.gov

Phone: (509) 375-2997. Fax: (509) 371-7249

Contents of SI: Total four pages containing two tables and five figures. 

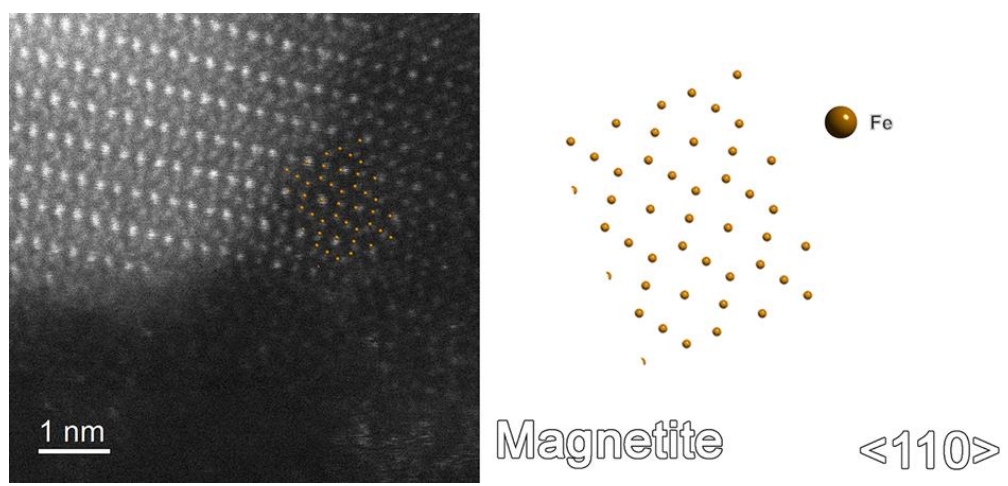

Figure S1. STEM (HAADF) of the $<110>$ of magnetite and ball and stick overlay of magnetite (note only the Fe atoms are shown). On the left hand side of the image two $<110\rangle$ crystals are overlapped, as compared to a single crystal on the right hand side of the image.

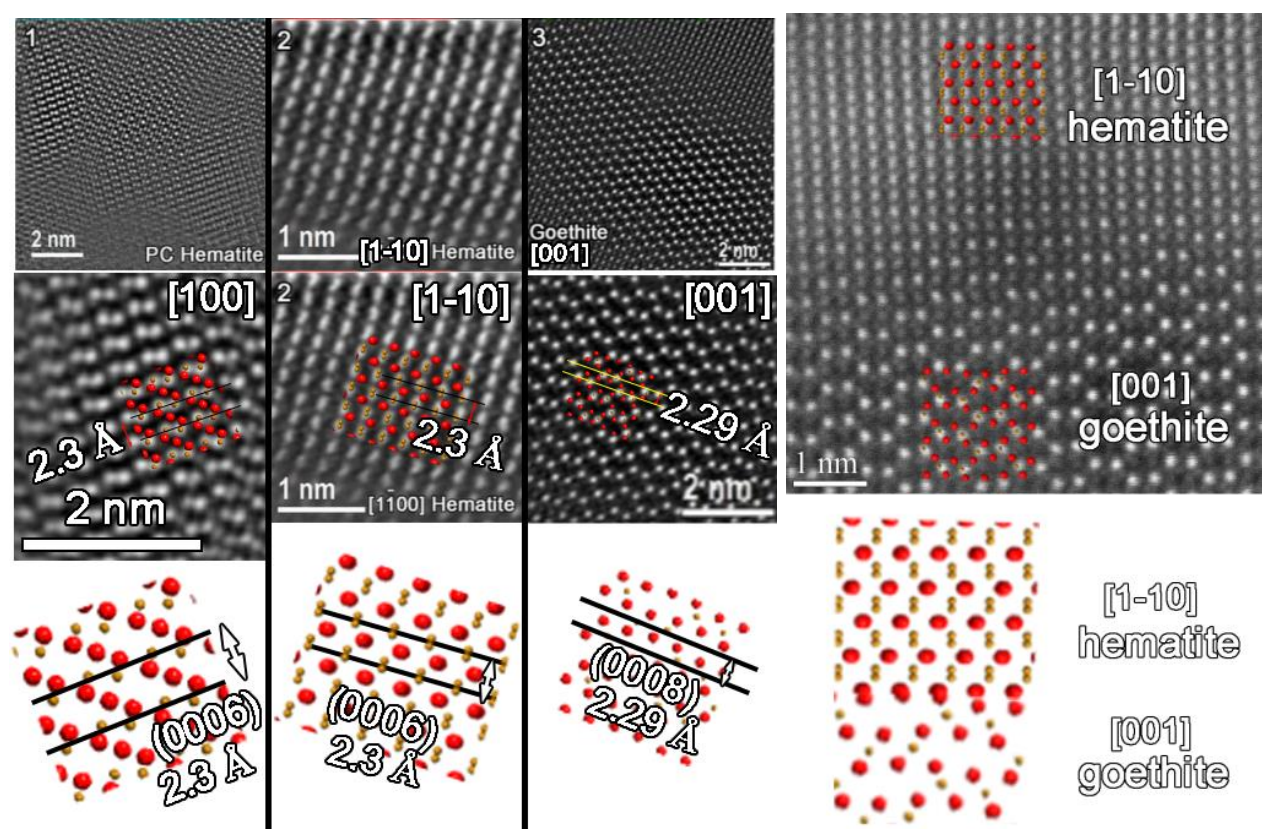

Figure S2. Filtered STEM (HAADF) and simulated ball and stick models of the various crystal phases observed in the sample. The d-spacing for listed planes are illustrated both in overlays as well as ball and stick models to illustrate the crystal structures are correctly identified. 


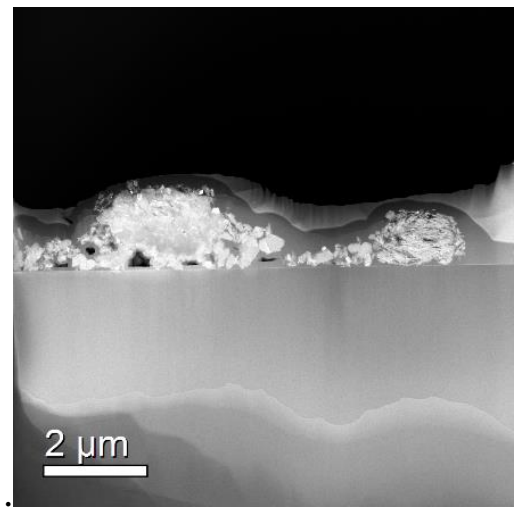

Figure S3. FIB-TEM specimen preparation with carbon and Pt coatings through the drop cast product on a Si substrate.

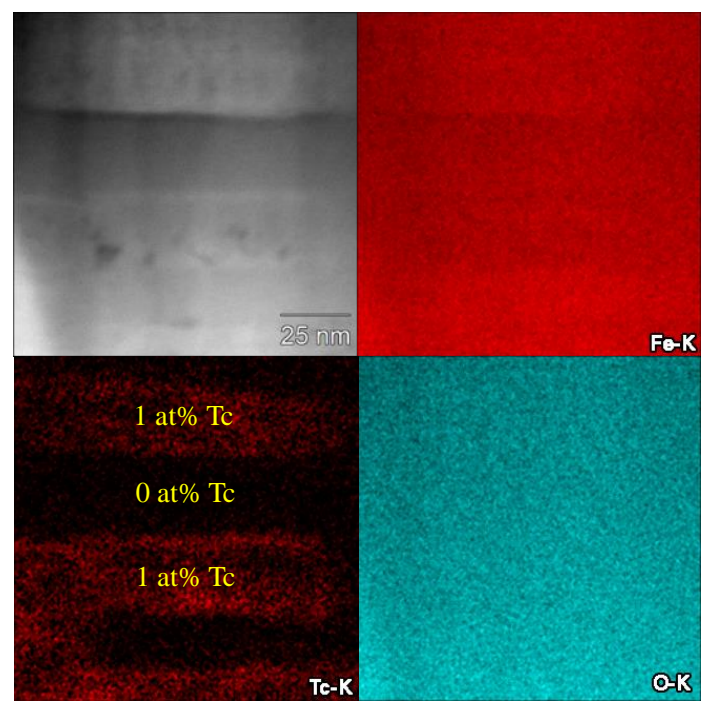

Figure S4. Extra examples of the stratified layers of magnetite showing no-Tc and Tc up to $\sim 1$ at. $\%$. 

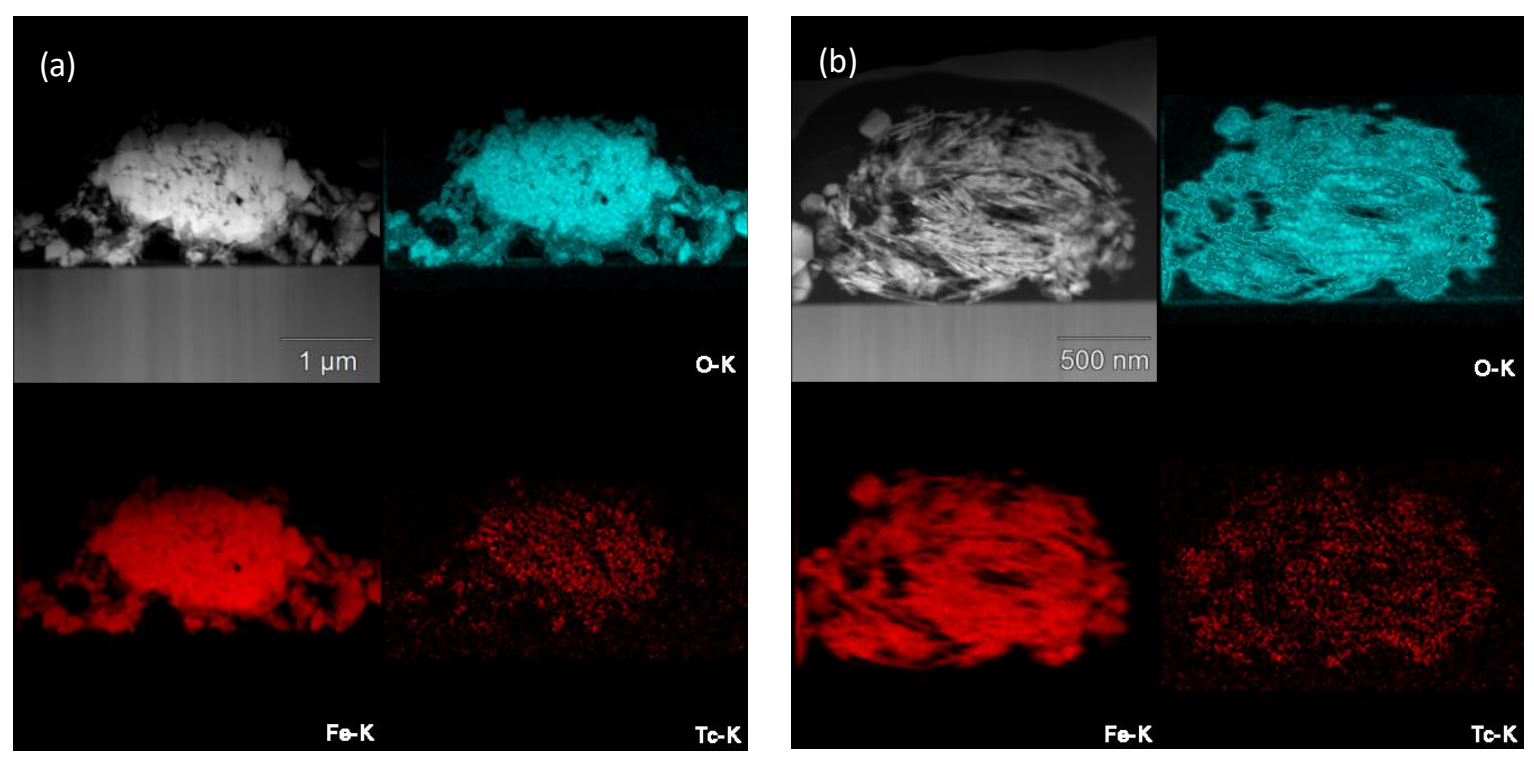

Figure S5. Tc distribute within the entire bundles of (a) blocky, plated magnetite domain, and (b) fibrous nanocrystal phases.

Table S1. Batch experimental results on Tc removal

\begin{tabular}{|c|c|c|c|c|}
\hline Batch vial & $\begin{array}{c}\mathrm{Fe}(\mathrm{OH})_{2}(\mathrm{~s}) \\
\text { weight }\end{array}$ & $\begin{array}{c}\mathrm{Tc}(\mathrm{VII}) \text {-spiked } 1 \mathrm{M} \\
\mathrm{NaOH} \text { solution volume }\end{array}$ & $\begin{array}{c}\text { ICP-MS } \\
\text { concentration }\end{array}$ & Tc removal \\
\hline & [g] & {$[\mathrm{mL}]$} & [ug/L] & [\%] \\
\hline Batch reactor & 0.18 & 40 & 1670 & 96.7 \\
\hline Control vial & 0 & 40 & 50700 & - \\
\hline
\end{tabular}

Table S2. Chemical composition of the Tc-containing fibrous nanocrystal phases. (corresponding to Figure S5b)

\begin{tabular}{|c|c|}
\hline Element & Atomic $\%$ \\
\hline $\mathrm{O}$ & 65.1 \\
\hline $\mathrm{Fe}$ & 34.1 \\
\hline $\mathrm{Tc}$ & 0.8 \\
\hline
\end{tabular}

